\title{
Oral peroxidases: From antimicrobial agents to ecological actors (Review)
}

\author{
PHILIPPE COURTOIS \\ Faculty of Medicine, Université Libre de Bruxelles, B-1070 Brussels, Belgium
}

Received February 8, 2021; Accepted April 7, 2021

DOI: $10.3892 / \mathrm{mmr} .2021 .12139$

\begin{abstract}
Sialoperoxidase and myeloperoxidase are the two main peroxidase enzymes found in the oral cavity. Sialoperoxidase is present in salivary secretions and in the biofilms that line the oral surfaces, while myeloperoxidase is abundant in the dento-gingival sulcus area. In the presence of hydrogen peroxide $\left(\mathrm{H}_{2} \mathrm{O}_{2}\right)$, oral peroxidases catalyze the oxidation of the pseudohalide anion thiocyanate $\left(\mathrm{SCN}^{-}\right)$ to hypothiocyanite $\left(\mathrm{OSCN}^{-}\right)$, a strong oxidant that serves an antimicrobial role. Furthermore, oral peroxidases consume bacteria-produced $\mathrm{H}_{2} \mathrm{O}_{2}$ and could help inactivate toxic carcinogenic and genotoxic substances. Numerous in vitro studies have reported the antibacterial, antimycotic and antiviral role of peroxidases, suggesting possible applications in oral therapy. However, the use of oral hygiene products incorporating peroxidase systems has not yet been shown to be beneficial for the treatment or prevention of oral infections. This paradox reflects our incomplete knowledge of the physiological role of peroxidases in a complex environment, such as the oral region. While hygiene is crucial for restoring oral microbiota to a symbiotic state, there are no data to suggest that the addition of a peroxidase per se can create a dysbiotic state. Recent investigations have associated the presence of peroxidase activity with gram-positive cocci microbial flora, and its insufficiency with dysbiosis has been linked to pathologies, such as caries, periodontitis or infections of the oral mucosa. Therefore, oxidants generated by oral peroxidases appear to be an essential ecological determinant for oral health through the selection of a symbiotic microbiota capable of resisting oxidative stress. The objective of the present review was to update the current knowledge of the physiological aspects and applications of oral peroxidases in clinical practice.
\end{abstract}

Correspondence to: Dr Philippe Courtois, Faculty of Medicine, Université Libre de Bruxelles, Route de Lennik 808, B-1070 Brussels, Belgium

E-mail: philippe.courtois@ulb.be; courtois.stas@skynet.be

Key words: biofilm, hypoiodite, hypothiocyanite, myeloperoxidase, oral hygiene, oral microflora, salivary peroxidase

\section{Contents}

1. Introduction

2. Oral peroxidases: Enzymes and substrates

3. Oxidant production by oral peroxidases

4. Biological roles of oral peroxidases

5. Mimicking biological systems

6. Conclusion

\section{Introduction}

Oral peroxidases are part of the innate non-immune defense mechanism of the saliva $(1,2)$. In the oral medium in the presence of hydrogen peroxide $\left(\mathrm{H}_{2} \mathrm{O}_{2}\right)$, these enzymes catalyze the oxidation of thiocyanate $\left(\mathrm{SCN}^{-}\right)$, a pseudohalide, into hypothiocyanite $\left(\mathrm{OSCN}^{-}\right)$, a powerful oxidant capable of inhibiting numerous bacterial species, mycoplasmas, fungi and viruses in vitro (Fig. 1). Sialoperoxidase and myeloperoxidase are the two main peroxidases found in the oral cavity. Sialoperoxidase is present in salivary secretions and in the biofilms that line the oral surfaces, while myeloperoxidase is abundant in the dento-gingival sulcus area $(3,4)$. By regulating the commensal oral flora, as well as by consuming bacterial $\mathrm{H}_{2} \mathrm{O}_{2}$, which is toxic for the oral mucosa, oral peroxidases help protect the tissues bordering the oral cavity from microbial injuries. Although numerous studies have demonstrated an antimicrobial role in vitro, only a few studies have documented the use of oral hygiene products incorporating peroxidase systems for the treatment or prevention of oral infections. This paradox reflects our incomplete knowledge of the physiological role of these enzymes in a complex environment, such as the oral environment. The aim of this review was to update our current knowledge of the physiological aspects of oral peroxidases, as well as their potential applications in the oral clinic. The relevant articles published in English until August 2020 were retrieved from the literature indexed by PubMed (https://pubmed.ncbi. nlm.nih.gov). The MeSH terms were 'thiocyanate', 'hydrogen peroxide' and 'iodide' with 'oral peroxidases' in different combinations without exclusion criteria, provided they are related to the interested topic area. The systematic attention to the bibliographic section of the papers so-selected was a second source of references. The review data have been neither statically processed nor organized into flowcharts. The quality of evidence for clinical trials follows the recommendations of 
the Grading of Recommendations Assessment, Development and Evaluation system.

\section{Oral peroxidases: Enzymes and substrates}

Peroxidase activity in the saliva was first suspected due to the restoration of an anti-lactobacillus effect following the addition of lactoperoxidase purified from bovine milk in heat-treated saliva $(5,6)$. Salivary peroxidase was then considered to be similar, if not identical, to lactoperoxidase. Salivary peroxidase (or sialoperoxidase) was not considered to be an enzyme different from lactoperoxidase until later. Indeed, these two enzymes have the same amino acid composition (7) and exhibit immunological cross-reactivity (8). However, they differ in their carbohydrate composition and certain kinetic characteristics (7). The whole saliva also contains a significant amount of myeloperoxidase from neutrophils, which enter the oral cavity through the dento-gingival sulci (3). The coexistence of sialoperoxidase and myeloperoxidase in the oral environment may mask the activity of other peroxidases that may be present in much lower quantities (microbial peroxidases) or transiently (lactoperoxidase in dairy products).

Sialoperoxidase. The parotid and submaxillary salivary glands secrete human sialoperoxidase from birth at adult concentrations $(9,10)$. Human sialoperoxidase occurs in different forms based on molecular weight and electrophoretic migration; sialoperoxidase may be free or linked to other salivary molecules, such as mucin (11-13). When unbound and monomeric, its molecular weight is $\sim 78,000$ (7), and its isoelectric point is 8-10 (11,14). This enzyme adsorbs different oral surfaces, while retaining its enzymatic activity (15-17), including enamel (15), dental plaque (18), salivary sediments (16) and bacteria such as streptococci (17). Other exocrine secretions, such as tears, sweat, airways or digestive secretions, also have a similar activity (usually referred to as lactoperoxidase and, at times, lacrimal peroxidase in tears). Salivary peroxidase, along with other proteins secreted by salivary glands (i.e. lysozyme and lactoferrin), participates in the antimicrobial protection of oral surfaces, such as mucosa and dental crowns.

Myeloperoxidase. Myeloperoxidase in saliva comes from the lysis of neutrophils entering the oral cavity by the dento-gingival sulci from the first dental eruptions (19-24). The leukocyte count in saliva decreases in edentulous patients and increases in oral inflammation processes (25). The number of neutrophils migrating into the oral cavity is $\sim 10^{6}$ cells $/$ min in healthy subjects, and higher in patients with periodontal disease $(3,26,27)$. In the saliva, neutrophils undergo hypo-osmotic shock and release myeloperoxidase along with other antimicrobial proteins, such as lysozyme and lactoferrin; in a similar manner, the salivary glands secrete the same two proteins, in addition to sialoperoxidase. Myeloperoxidase represents up to $20-25 \%$ of the total peroxidase activity in total centrifuged resting saliva, while it predominates in the salivary sediment and in the liquid of the dento-gingival sulci, where it participates in antimicrobial tissue protection $(3,23)$. The primary substrate for myeloperoxidase is chloride $\left(\mathrm{Cl}^{-}\right)$in the tissues [with the production of hypochlorite $\left(\mathrm{OCl}^{-}\right)$] and $\mathrm{SCN}^{-}$in the saliva (with the production of $\mathrm{OSCN}^{-}$).
Lactoperoxidase in dairy products. Lactoperoxidase, similarly to sialoperoxidase, catalyzes the oxidation of $\mathrm{SCN}^{-}$in vivo and iodide ( $\left.\mathrm{I}^{-}\right)$in vitro, in the presence of $\mathrm{H}_{2} \mathrm{O}_{2}$. Easily purified from bovine milk, lactoperoxidase was first characterized and its enzymatic aspects were specifically documented by Aune and Thomas in 1977 and $1978(28,29)$. Lactoperoxidase was commonly used to study the effects of a peroxidase- $\mathrm{H}_{2} \mathrm{O}_{2}-\mathrm{SCN}^{-}$ system on cariogenic bacteria, such as oral streptococci (30) or Lactobacillus acidophilus (31), on periodontopathogenic bacteria (32). The lactoperoxidase-SCN- combination is used as a preservative for vegetables and as a supplement in several oral hygiene products. The lactoperoxidase-I' combination allows for the radioactive labelling of proteins. Lactoperoxidase has the property of adsorbing different surfaces, including that of biomaterials, such as titanium (33).

$\mathrm{H}_{2} \mathrm{O}_{2}$. Oral $\mathrm{H}_{2} \mathrm{O}_{2}$ comes from the salivary glands [DUOX family of oxidases, reviewed in (34)], neutrophils [NOX family of oxidases, reviewed in (35)] and particularly certain bacterial species present in the mouth through the action of pyruvate oxidase (36). $\mathrm{H}_{2} \mathrm{O}_{2}$ is one of the reactive oxygen species (ROS) synthesized by neutrophils during phagocytosis and secreted by the salivary glands as a trigger for sialoperoxidase activity. Determination of $\mathrm{H}_{2} \mathrm{O}_{2}$ in the saliva is challenging, given its rapid consumption by oral peroxidases and bacterial catalases. Most of the oral $\mathrm{H}_{2} \mathrm{O}_{2}$ comes from bacteria of the genus Streptococcus (37-39) and, to a much lesser extent, from optional anaerobes $(40,41)$. Based on the equilibrium constant of the $\mathrm{SCN}^{-}$peroxidation reaction $\left(3.7 \times 10^{3} \mathrm{M}^{-1}\right)$ in the oral medium, the mean salivary $\mathrm{H}_{2} \mathrm{O}_{2}$ concentration has been estimated at $10 \mu \mathrm{M}(42)$, the maximum dose tolerable by mammalian cells $(43,44)$. At low concentrations $(1-10 \mathrm{nM})$, $\mathrm{H}_{2} \mathrm{O}_{2}$ plays a role as a signaling molecule in bacteria-bacteria interactions $(45,46)$. For example, $\mathrm{H}_{2} \mathrm{O}_{2}$ can promote the formation of Streptococcus parasanguinis biofilms co-cultured with Actinobacillus actinomycetemcomitans in vitro (47).

$S C N^{-}$. SCN- is secreted by the parotid, submaxillary, sublingual and minor salivary glands $(48,49)$ at a concentration that is dependent on exogenous intake, mainly brassica vegetables (50), as well as the smoking habits of individuals (51), and on endogenous production coupled with the detoxification of food cyanide, such as cassava (52). The salivary concentration of $\mathrm{SCN}^{-}$is $0.5-2 \mathrm{mM}$ in non-smokers and may be up to $10 \mathrm{mM}$ in heavy smokers $(12,51,53)$; its concentrations in the gingival crevicular fluid is $\sim 40 \mu \mathrm{M}$, but may be higher in smokers (12). Of note, the optimal levels for peroxidase activity are in the order of $\mathrm{mM}$. To the best of our knowledge, no study to date has documented the harmful effect of smoking on oral health through the inhibition of the natural peroxidase systems. $\mathrm{SCN}^{-}$has already been proposed as a vasodilator to combat hypertension or as an antimicrobial agent in combination with a peroxidase system. In this context, various studies [reviewed in (54)] have suggest the absence of $\mathrm{SCN}^{-}$toxicity up to concentrations sufficient to activate the enzymatic production of $\mathrm{OSCN}^{-}$. A more significant increase in plasma $\mathrm{SCN}^{-}$concentration is linked to the inhibition of thyroid function, particularly in cases of iodine deficiency. Indeed, $\mathrm{SCN}^{-}$is a competitive inhibitor of the $\mathrm{Na}^{+} / \mathrm{I}^{-}$symport in thyroid follicular cells. This competition between a halogen 


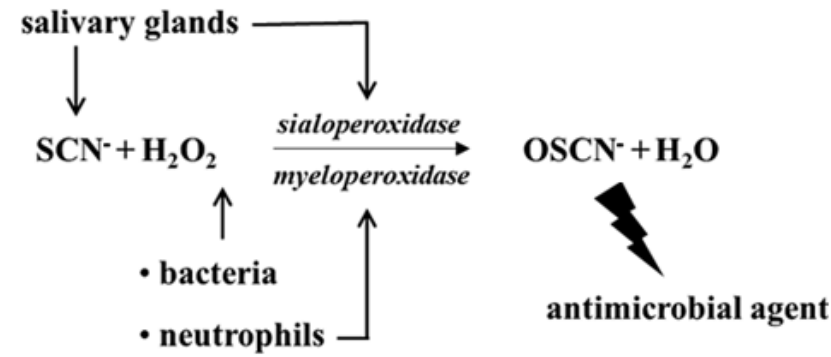

Figure 1. Peroxidase system in the oral cavity leading to the production of $\mathrm{OSCN}^{-}$, which controls the oral microflora. $\mathrm{SCN}^{-}$, thiocyanate; $\mathrm{H}_{2} \mathrm{O}_{2}$, hydrogen peroxide; $\mathrm{OSCN}^{-}$, hypothiocyanite.

and $\mathrm{SCN}^{-}$for peroxidases explains the etymology of the word 'pseudohalogen' to qualify for $\mathrm{SCN}^{-}$.

$I^{-}$. The ability of the salivary glands to concentrate $\mathrm{I}^{-}$into the salivary compartment (20-100 times higher than the plasma concentration) has long been known (55). This capacity for concentrating iodine in saliva before intestinal re-absorption contributes to the preservation of the iodine pool for optimal thyroid function (56). Iodine deficiency, which is marked by lower urinary and salivary rates, has been correlated with an increase in the incidence of dental caries (57), but no association between iodine deficiency and oral peroxidases has been reported in these studies. Other studies have implicated iodine deficiency in immune dysfunctions (56). Excess iodine has been reported to induce alterations of the salivary glands, including lymphocytic infiltrations (58), in an animal model. In vitro, $\mathrm{I}^{-}$is another substrate for sialoperoxidase, myeloperoxidase or lactoperoxidase in antimicrobial systems. The salivary concentration of $\mathrm{I}^{-}$in humans is estimated to be insufficient for antimicrobial action in vivo. Indeed, the salivary levels reported in the literature are in the order of $\mu \mathrm{M}(1,59,60)$, while those of $\mathrm{SCN}^{-}$are in the $\mathrm{mM}$ range. The ability of $\mathrm{SCN}^{-}$to inhibit the uptake of $\mathrm{I}^{-}$by the parotid cells in parallel with thyroid cells has long been known (61). The presence of $\mathrm{SCN}^{-}$at higher concentrations in the saliva should limit the metabolism of $\mathrm{I}^{-}$(oxidation, iodination of tyrosine and iodination of proteins) $(12,62,63)$. However, certain studies have suggested a synergy between the two substrates (64), whereas others have documented the in vitro formation of iodine- $\mathrm{SCN}^{-}$complexes as a more active/stable antimicrobial component, as compared with $\mathrm{OI}^{-}$and $\mathrm{OSCN}^{-}$alone (65-68).

\section{Oxidant production by oral peroxidases}

Both peroxidases that present in the oral cavity transform SCN into $\mathrm{OSCN}^{-}$. In vitro, sialoperoxidase turns $\mathrm{I}^{-}$into hypoiodite $\left(\mathrm{OI}^{-}\right)$. In tissues, myeloperoxidase forms $\mathrm{OCl}^{-}$from $\mathrm{Cl}^{-}$but not in saliva due to the presence of $\mathrm{SCN}^{-}$. In vitro, myeloperoxidase can also produce $\mathrm{OI}^{-}$. In the oral environment, the two peroxidases oxidize $\mathrm{SCN}^{-}$more abundantly than $\mathrm{I}^{-} . \mathrm{H}_{2} \mathrm{O}_{2}$ is a factor limiting the activity of oral peroxidases. These non-Michaelian enzymes are characterized by optimal concentrations, above which their substrates become their inhibitors (69).

It should be noted that the oral cavity is not a single homogeneous compartment, but rather a juxtaposition of sites, each characterized by its own ecosystem. The intraoral sites to be considered are indeed numerous and can be grouped into the saliva, biofilms and dento-gingival sulci (70). The peroxidase activity varies across sites, depending on the concentrations of available substrates $\left(\mathrm{H}_{2} \mathrm{O}_{2}\right.$ and $\left.\mathrm{SCN}^{-}\right)$. The parotid production of $\mathrm{H}_{2} \mathrm{O}_{2}$ is already sufficient for generating $\mathrm{OSCN}^{-}$in the excretory Stenson's duct (71). The preferred method for determining salivary $\mathrm{OSCN}^{-}$is based on the oxidation of the 5,5'-dithiobis-2-nitrobenzoic acid (72). Other procedures are based on the oxidation of pyrogallol, guaiacol or ABTS (73). However, these methods, which are not specific to $\mathrm{OSCN}^{-}$, do not make it possible to specifically analyze the products of the peroxidase activity in the presence of several substrates during the same test, in this case $\mathrm{SCN}^{-}$together with $\mathrm{I}^{-}$. A colorimetric method in the presence of tetramethylbenzidine was recently developed to more specifically assess $\mathrm{OI}^{-}$(74). Fluorides have been described as inhibitors of lactoperoxidase and sialoperoxidase at acid $\mathrm{pH}$ regardless of the substrate, $\mathrm{SCN}^{-}$or $\mathrm{I}^{-}(75)$.

$O S C N^{-}$. OSCN- is considered to be the major oxidant produced by oral peroxidases in the oral cavity. Concentrations of $\mathrm{OSCN}^{-}$up to $300 \mu \mathrm{M}$ have been reported in the literature for the whole saliva (12). However, methodological problems when collecting samples may lead to default errors due to the instability of the molecule and the large number of oxidizable targets in saliva and oral biofilms. As $\mathrm{SCN}^{-}$is metabolized by both myeloperoxidase and sialoperoxidase, the production of $\mathrm{OSCN}^{-}$alone cannot be used to characterize the activity of one of these two enzymes (76). $\mathrm{OSCN}^{-}$at the doses required for an antibacterial effect does not appear to cause damage to the genetic material of the mucous membranes (77). However, selective oxidation of cell/tissue targets containing thiol groups could initiate significant cell damage, such as damage to gingival epithelial cells (78).

$\mathrm{OI}^{-}$. In vitro, $\mathrm{OI}^{-}$decreases the survival rate of some microbial species at a lower concentration, as compared with that observed for $\mathrm{OSCN}^{-}$, especially in Candida albicans (79). Some authors (80) have been able to demonstrate that ${ }^{125} \mathrm{I}$ only binds to a limited number of membrane molecules of Candida albicans, which is particularly sensitive to $\mathrm{OI}^{-}$. However, the hypohalous ion present in the oral cavity is $\mathrm{OSCN}^{-}$rather than $\mathrm{OI}^{-}$, as the substrate $\mathrm{SCN}^{-}$at the origin of the former is 1,000 times more abundant, as compared with $\mathrm{I}^{-}$at the source of the latter. The salivary $\mathrm{SCN}^{-}$concentration reaches the $\mathrm{mM}$ level, while $\mathrm{OI}^{-}$barely reaches concentrations in the $\mu \mathrm{M}$ range. At equal (pseudo)halide concentrations, lactoperoxidase has a higher affinity for $\mathrm{SCN}^{-}$than for $\mathrm{I}^{-}$. However, experimentally, the substitution of $\mathrm{SCN}^{-}$by $\mathrm{I}^{-}$increases the innate antiviral defences of the respiratory mucosa against adenoviruses and the respiratory syncytial virus (81). Oral administration of KI vs. NaI increases iodemia, allowing for the accumulation of $\mathrm{I}^{-}$in the mucous secretions of the upper respiratory tract in humans (81) as well as animals $(82,83)$. Although it has already been demonstrated that $\mathrm{I}^{-}$accumulates in submandibular glands in hamsters (84), no similar observations have been reported in humans. It would be interesting to be able to specifically assess salivary $\mathrm{OI}^{-}$in excretory ducts, such as the Stenson's duct, where the oral biofilms do not extend, except in the case of infectious parotitis. Finally, the 
success of topical formulations based on povidone-iodine to reduce bacterial growth in the oral cavity in ventilated patients may be attributed to the increase in $\mathrm{I}^{-}$available for the patient's peroxidases (85).

Iodine-thiocyanate complexes. The two substrates of peroxidase, $\mathrm{SCN}^{-}$and $\mathrm{I}^{-}$, have been mostly tested independently in suspensions, and less frequently in combination (64). Moreover, few articles reporting that the activity of lactoperoxidase produces a mixture of OSCN/OI ${ }^{-}$in the presence of a mixture of $\mathrm{SCN}^{-} / \mathrm{I}^{-}$substrates have effectively analyzed the products generated under their experimental conditions $(1,64,86)$. Mixtures of the two substrates, $\mathrm{SCN}^{-}$and $\mathrm{I}^{-}$, however, appear to lead to the formation of a more stable oxidative complex over time $(65,66,87-90)$. Under well-defined in vitro experimental conditions (high ionic strength; $\mathrm{KI}: \mathrm{KSCN}$ ratio, 4.5; neutral or acidic buffer; presence of $\mathrm{H}_{2} \mathrm{O}_{2}$ ), lactoperoxidase produces stable iodine-SCN ${ }^{-}$complexes, such as $\mathrm{I}_{2}(\mathrm{SCN})^{-}$, objectified by carbon-13 (C13) nuclear magnetic resonance spectroscopy (66) with antimicrobial properties against Candida (67). Oxidant concentrations are then less toxic to epithelial cells in the mouth, as compared with chlorhexidine (67). The resistance of epithelial cells may be explained by the presence of bacteria covering their surface and forming a protective biofilm, and/or by the detoxification of enzymatic activities in certain commensal species present in the oral environment (91). The use of these complexes for rinsing dentures ex vivo further limits the possible effect on epithelial cells in vivo. The

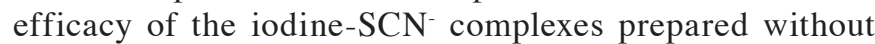
peroxidase activity has already been demonstrated in vitro on Pseudomonas aeruginosa and Staphylococcus aureus, both in suspension and in biofilms (92). Other studies will have to analyze the interference between this solution of iodine-SCN complexes and oral microbial ecology.

\section{Biological roles of oral peroxidases}

Over several decades, oral peroxidases have been recognized as being essential for oral health (93), despite the absence of clinical evidence. Indeed, no specific deficit in sialoperoxidase or its association with a particular pathology have been described. Although the decrease in salivary flow leads to carries or mucosa infections (for example, candidiasis), the deficiency of no particular salivary molecule (in this case, sialoperoxidase) has been definitively proven to cause these infections. Similarly, neutropenia leads to gingivitis/ periodontitis, but it is not possible to definitively deduce that myeloperoxidase deficiency is individually responsible. The demonstration of the biological roles of peroxidases is based more on in vitro studies carried out under physiological conditions.

Antimicrobial effects. Oral peroxidases control the oral microbiota while detoxifying the environment of $\mathrm{H}_{2} \mathrm{O}_{2}$. By oxidizing thiol groups (29) and nicotinamide adenine dinucleotide phosphate $(\mathrm{NAD}(\mathrm{P}) \mathrm{H})(94), \mathrm{OSCN}^{-}$exerts antimicrobial, antimycotic and antiviral effects $(1,2)$. In particular, the bacterial hexokinase activity, which initiates the Emden-Meyerhoff pathway, decreases in the presence of $\mathrm{OSCN}^{-}$. Acid production by dental plaque is reduced in the presence of $\mathrm{OSCN}^{-}(95)$.
In vitro, $\mathrm{OSCN}^{-}$slows the growth of cariogenic bacteria belonging to the genera Streptococcus or Lactobacillus (1). Periodontopathogenic bacteria are also inhibited (32,96-98), as are yeasts of the Candida genus, which are responsible for mucosal pathologies (99). Some viruses are sensitive to this oxidant, such as the herpes virus (100), HIV (101) or influenza virus $(102,103)$. Antisepsis research suggests using peroxidase-generated $\mathrm{OSCN}^{-}$as a putative prophylactic agent to prevent contamination with SARS-CoV-2 (104).

Some bacteria have developed various strategies to resist the ROS produced by neutrophils (105). Similarly, commensal oral surface bacteria, such as Streptococcus sanguis (one of the first colonizers of the dental plaque) have the biochemical equipment to protect themselves from $\mathrm{OSCN}^{-}$. By contrast, Streptococcus mutans (a cariogenic bacterial species) does not have this detoxifying system (91). Thus, peroxidases operate more like ecological selectors by allowing commensal bacteria capable of reducing $\mathrm{OSCN}^{-}$to survive in the oral environment. Moreover, peroxidases coupled to a system detoxifying the environment of hypohalous compounds (of the thioredoxin type) participate in the protection of tissues against oxidants resulting from the metabolism of activated oxygen, such as the superoxide anions or $\mathrm{H}_{2} \mathrm{O}_{2}(106)$. There appears to be an interconnection between resistance to oxidative stress and the ability to form biofilms via quorum-sensing molecules, such as farnesol (107). On the other hand, non-active lactoperoxidase, after the depletion of the substrate, can promote the in vitro growth of certain anaerobes (98). At the same time, a clinical study (108) suggested a rebound in periodontitis after a phase of clinical improvement, possibly due to an accumulation of lactoperoxidase without substrate. The association of a peroxidase system with another innate non-immune defence factor further strengthens the inhibition of some bacteria in vitro. For example, lysozyme improves the inhibition of glucose metabolism by the peroxidase system in Streptococcus mutans (109).

Biofilm control. Sialoperoxidase, similar to lactoperoxidase in vitro, adsorbs enamel surfaces irreversibly (15) while retaining its activity. This property contributes to controlling the formation of dental plaque and regulating the bacterial microflora attached to the surfaces of the oral cavity. The activity of peroxidases present in dental plaque depends on the availability of its two substrates $\left(\mathrm{SCN}^{-}\right.$and $\left.\mathrm{H}_{2} \mathrm{O}_{2}\right)$ in the thickness of oral biofilms. $\mathrm{SCN}^{-}$diffuses deeper into the biofilms from the salivary film that covers them. At the same time, $\mathrm{H}_{2} \mathrm{O}_{2}$ relies on the oxygen supply allowing certain bacteria to produce it in situ. Certain studies $(12,106)$ have described a virtuous cycle summarizing the beneficial effect of sialoperoxidase on oral microflora control. After a supply of food sugars, commensal bacteria of the genus Streptococcus grow and produce more $\mathrm{H}_{2} \mathrm{O}_{2}$, which activates the production of $\mathrm{OSCN}^{-}$in the presence of sialoperoxidase and $\mathrm{SCN}^{-}$, thereby limiting bacterial growth or even killing microorganisms. Theoretically, these mechanisms work less effectively deeper inside thick biofilms, given the consumption of peroxidase substrates in the most superficial layers. Similarly, mouth rinsing with solutions containing an $\mathrm{OSCN}^{-}$-generating system is likely to further impact the more superficial layers of biofilms. These remarks suggested that a peroxidase system 
may act both on the formation of biofilms and on already formed biofilms.

In addition to protecting the walls of the oral cavity, sialoperoxidase may also protect the excretory ducts of the salivary glands, which are rarely infected when they open into an oral cavity abundantly colonized by microbial germs; however, to the best of our knowledge, no scientific study has yet considered this physiological aspect.

Protection against oxidative stress. The uncontrolled production of activated oxygen species (ROS: Superoxides, $\mathrm{H}_{2} \mathrm{O}_{2}$, free radicals, hypohalous compounds) or reactive nitrogen species (RNS: Compounds derived from nitric oxide and superoxides, such as peroxynitrite, nitrogen dioxide and dinitrogen trioxide) is implicated in various oral pathologies (110). These oxidative derivatives damage cells and are considered to be mutagenic and carcinogenic. They are controlled in the salivary environment by scavengers (mainly uric acid) and antioxidant enzymes (bacterial catalase and oral peroxidases). Lactoperoxidase transforms cytotoxic $\mathrm{H}_{2} \mathrm{O}_{2}$ into a less toxic product, as suggested by in vitro experiments on fibroblast cultures (44). The coupling of peroxidases to a bacterial thioredoxin system helps protect tissues from oxidants produced from peroxidase activities. In tissues (including gingival), catalase and glutathione peroxidase help remove $\mathrm{H}_{2} \mathrm{O}_{2}$.

Certain studies [reviewed in (12)] considered that the enzymatic peroxidation of mutagenic and carcinogenic molecules bound to diet as another function of oral peroxidases. However, the related data are currently insufficient to assess its actual significance in the detoxification of toxic molecules introduced into the oral cavity, through food or other means.

\section{Mimicking biological systems}

Manufacturers have attempted to mimic the peroxidase activity of saliva by incorporating lactoperoxidase into oral hygiene products [reviewed in (111)]. A 'peroxidase system' is a galenic formulation associating a peroxidase with one of its substrates of the (pseudo)halide type plus $\mathrm{H}_{2} \mathrm{O}_{2}$ or an $\mathrm{H}_{2} \mathrm{O}_{2}$ donor. The formulation of such a system requires a methodical step-by-step approach to optimize the volume and rinsing time, the concentration of $\mathrm{H}_{2} \mathrm{O}_{2}$ and $\mathrm{SCN}^{-}$, as well as the $\mathrm{pH}$, in order to achieve the production of an adequate antimicrobial level in the oral cavity (112). Even before the launch of oral hygiene products with a peroxidase system, Food and Agriculture Organization (FAO)/World Health Organization (WHO) recommended its use for the safe preservation of raw milk or vegetables (113). Articles on proteins derived from milk list the oral benefits of lactoperoxidase, sometimes associated with other proteins, such as lactoferrin or lysozyme (114). Numerous preclinical in vitro tests (through saliva sample collection, solid or liquid cultures, biofilm models) have evaluated peroxidase systems for pharmacokinetics (115), antimicrobial effects on the oral microflora (116), as well as toxicity on epithelial cells (117). Some ex vivo studies have reported the decontamination of materials that have remained in an oral environment, while others describe the advantage of their use in vivo. The $\mathrm{SCN}^{-} /$lactoperoxidase system is the most extensively investigated, but there have been few clinical studies on the I//lactoperoxidase system (118).
Unfortunately, these investigations often test a peroxidase system coupled with other milk antimicrobial proteins also found in the saliva (119). Such systems have been introduced into oral hygiene products with a curative intent (periodontitis, halitosis) or with a preventive perspective (dry mouth, caries). However, the efficacy of these products has not been sufficiently documented (117), and there are only a limited number of small-scale phase I/II clinical trials. Investigators face the difficulty of finding adequate biological markers to demonstrate the effects of a peroxidase system on the regulation of oral microflora in the oral environment. Another dilemma could be to choose between quantitative (bacterial count) or qualitative (metabolic markers) markers. For example, a mouth-rinse/tooth-wash with an in vivo peroxidase system increases the concentration of $\mathrm{OSCN}^{-}$in the saliva (120) but does not change the total number of salivary bacteria, while it could reduce bacterial ATP (an indicator of their metabolic potential). Several studies have thoroughly evaluated peroxidase systems by following clinical indices (gingival index, plaque index, etc.) and some others, as dry mouth, settle for satisfaction surveys. The determination of an appropriate control is challenging. Moreover, the short half-life of the oxidants produced and the bacterial resistance constitute other limitations to their use. Recently, the $\mathrm{SCN}^{-} / \mathrm{I}^{-}$combination has made it possible to obtain more stable products. Molecular techniques (16SrRNA gene sequencing analysis) demonstrated that the use of lactoperoxidase coupled with lactoferrin promotes supragingival and lingual biofilms with more gram-positive and fewer gram-negative bacteria (119).

Tables I and II list the clinical studies evaluating a peroxidase system used alone $(108,121-130)$ or in combination (131-140) with other exocrine proteins.

Curative vs. preventive. The use of peroxidase systems may be considered as topical administration to protect oral surfaces in vivo as a prophylactic measure. Recommending these galenic preparations may not be of value as a curative approach, as the infection itself indicates that a deregulated oral flora has overtaken physiological systems, including peroxidase. Reserving or even developing these galenic preparations as prophylactic treatment would avoid the appearance of strains resistant to antimicrobials used continuously to prevent the occurrence of certain infections (for example, oral candidiasis in patients with AIDS).

In vitro vs. in vivo. Peroxidase systems present a paradox: Although they have been shown to be active in vitro for a long time, the definitive evidence of their effects in vivo is still lacking. A possible explanation is the actual availability of $\mathrm{H}_{2} \mathrm{O}_{2}$ in the oral environment, which is rich in bacterial catalase. In this case, the increased availability of $\mathrm{H}_{2} \mathrm{O}_{2}$ can compensate for its consumption by other enzymatic activities $(141,142)$, thus allowing the exogenous lactoperoxidase to be active. Another explanation would be to consider a transient metabolic suppression demonstrated, for example, by assaying ATP, but not observed on culture media.

In vivo vs. ex vivo. Peroxidases adsorb different biomaterials used in dentistry: Titanium and resin are two examples. Ex vivo use may be employed to disinfect removable prostheses 


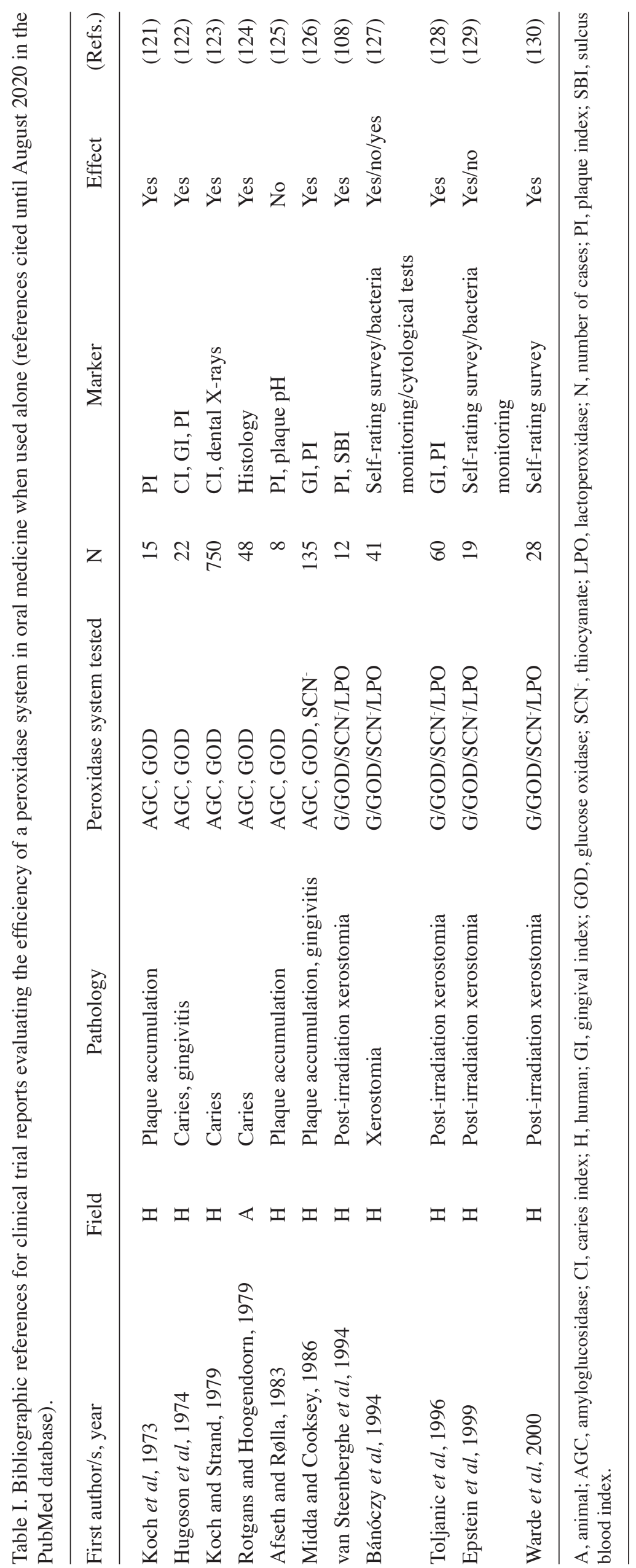




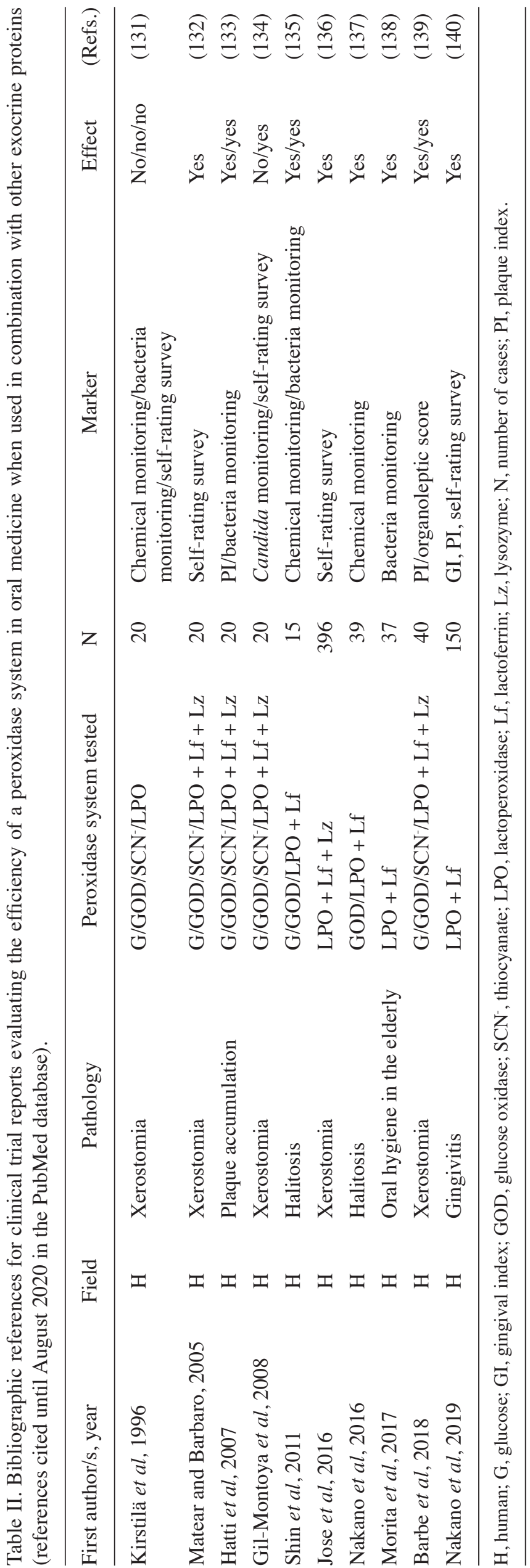


by short-circuiting in vivo use; the intra-oral administration is indeed considered by some to be dangerous, due to cytotoxicity and potential immunogenicity. The toxicity of peroxidase systems on the oral mucosa appears to be limited by the oral biofilms covering them. However, the accumulation of inactive lactoperoxidase in biofilms may favor certain anaerobic bacteria, such as Porphyromonas gingivalis (98). On the other hand, the accumulation of $\mathrm{I}^{-}$during regular use would not be advised for some patients. With regards to health and safety, it should be noted that the FAO recommends the $\mathrm{SCN}^{-} /$lactoperoxidase system for the decontamination of milk and vegetables for food sales (113).

Toxicity. Few reports have analyzed the oral toxicity of peroxidase systems when recommended in oral care products. Indirectly, these products may be beneficial for patients who have aphthous ulcers secondary to the toxicity of lauryl sulfate, often used as a detergent in toothpaste (143). Indeed, the incorporation of such enzymes in oral hygiene products implies the no-use of detergent foaming agents, which have the ability to denature proteins, and therefore enzymes.

Perspective in oral hygiene. Numerous investigations have analyzed the effects of peroxidase systems on the various pathogens present in the oral cavity, including viruses. In vivo, oral peroxidases defend the gingival sulcus against microbial invasion (myeloperoxidase) and help regulate the microflora adhering to the surfaces of the oral cavity (sialoperoxidase). Incorporating lactoperoxidase with other salivary antimicrobial proteins in salivary substitutes may mimic the antimicrobial effect of the salivary exocrine fluid (144). The beneficial effect of oral sprays with such peroxidase preparations in combating dryness of the oral mucosa in patients on respirator treatment has already been proposed. However, their benefit in daily oral hygiene has not yet been quantified or even demonstrated by clinical studies. Certain studies have suggested considering peroxidases as ecological selectors directing the oral microflora towards a Gram-positive cocci microflora poor in cariogenic or periodontopathogenic germs, thereby preserving the mucosa and protecting it from yeast overgrowth, among others. Thus, the administration of an efficient lactoperoxidase system in a toothpaste also containing lactoferrin and lysozyme may prevent oral dysbiosis (145). A few studies have demonstrated an inverse association between the activity of sialoperoxidase and the depth of the periodontal pockets (146). On the other hand, the administration of inactive peroxidase without substrate seems to disturb in vitro the balance between commensals and periodontopathogens to the latter's advantage $(98,147)$. The peroxidase systems' clinical benefit in oral hygiene must still be demonstrated on a large scale through evidence-based practice.

\section{Conclusion}

Oral peroxidases are involved in the control of the oral microflora as ecological selectors favoring a commensal flora, which can develop or survive in the presence of $\mathrm{OSCN}^{-}(148,149)$. The use of peroxidase systems may be beneficial for preventing topical administration to protect the oral surfaces in vivo. By contrast, they may be used ex vivo to disinfect removable prostheses. The efficacy of formulations with peroxidase activity is not yet sufficiently documented, and there are no large-scale clinical trials to date. The short half-life of the produced oxidants and bacterial resistance constitute limiting factors for their use. However, the $\mathrm{SCN}^{-} / \mathrm{I}^{-}$ combination has recently made it possible to obtain more stable products.

\section{Acknowledgements}

Not applicable.

Funding

No funding was received.

\section{Availability of data and materials}

Not applicable.

\section{Author's contributions}

PC conceived and designed the study, and drafted the manuscript. Data authentication is not applicable. The author read and approved the final manuscript.

\section{Ethics approval and consent to participate}

Not applicable.

\section{Patient consent for publication}

Not applicable.

\section{Competing interests}

The author declares that he has no competing interests.

\section{References}

1. Pruitt KM and Reiter B: Biochemistry of peroxidase system: Antimicrobial effects. In: The lactoperoxidase system: Chemistry and Biological Significance. Pruitt KM and Tenovuo JO (eds). Marcel Dekker, New York, pp143-178, 1985.

2. Bafort F, Parisi O, Perraudin JP and Jijakli MH: Mode of action of lactoperoxidase as related to its antimicrobial activity: A review. Enzyme Res 2014: 517164, 2014.

3. Thomas EL, Jefferson MM, Joyner RE, Cook GS and King CC: Leukocyte myeloperoxidase and salivary lactoperoxidase: Identification and quantitation in human mixed saliva. J Dent Res 73: 544-555, 1994.

4. Ihalin R, Loimaranta V and Tenovuo J: Origin, structure, and biological activities of peroxidases in human saliva. Arch Biochem Biophys 445: 261-268, 2006.

5. Morrison M,Allen PZ,Bright J and Jayasinghe W: Lactoperoxidase. $\mathrm{V}$. Identification and isolation of lactoperoxidase from salivary gland. Arch Biochem Biophys 111: 126-133, 1965.

6. Slowey RR, Eidelman S and Klebanoff SJ: Antibacterial activity of the purified peroxidase from human parotid saliva. J Bacteriol 96: 575-579, 1968

7. Mansson-Rahemtulla B, Rahemtulla F, Baldone DC, Pruitt KM and Hjerpe A: Purification and characterization of human salivary peroxidase. Biochemistry 27: 233-239, 1988.

8. Mansson-RahemtullaB,RahemtullaFandHumphreys-BeherMG: Human salivary peroxidase and bovine lactoperoxidase are cross-reactive. J Dent Res 69: 1839-1846, 1990. 
9. Gothefors L and Marklund S: Lactoperoxidase activity in human milk and in saliva of newborn infants. Infect Immun 11: 1210-1215, 1975.

10. Tenovuo J, Lehtonen OP, Aaltonen AS, Vilja P and Tuohimaa P Antimicrobial factors in whole saliva of human infants. Infect Immun 51: 49-53, 1986.

11. Tenovuo J: The peroxidase system in human secretions. In: The lactoperoxidase system: Chemistry and Biological Significance. Pruitt KM and Tenovuo J (eds). Marcel Dekker, New York, pp101-122, 1985

12. Tenovuo J: Nonimmunoglobulin defense factors in human saliva. In: Human saliva: Clinical chemistry and microbiology, Vol. 2. Tenovuo J (ed). Boca Raton, FL, CRC Press, pp55-91, 1989.

13. Mäkinen KK and Tenovuo J: Chromatographic separation of human salivary peroxidases. Acta Odontol Scand 34: 141-150, 1976.

14. Tenovuo J: Different molecular forms of human salivary lactoperoxidase. Arch Oral Biol 26: 1051-1055, 1981.

15. Pruitt KM and Adamson M: Enzyme activity of salivary lactoperoxidase adsorbed to human enamel. Infect Immun 17: 112-116, 1977.

16. Tenovuo J, Valtakoski J and Knuuttila ML: Antibacterial activity of lactoperoxidase adsorbed by human salivary sediment and hydroxyapatite. Caries Res 11: 257-262, 1977.

17. Pruitt KM, Adamson M and Arnold R: Lactoperoxidase binding to streptococci. Infect Immun 25: 304-309, 1979.

18. Cole MF, Hsu SD, Baum BJ, Bowen WH, Sierra Ll, Aquirre M and Gillepsie G: Specific and nonspecific immune factors in dental plaque fluid and saliva from young and old populations. Infect Immun 31: 998-1002, 1981.

19. Wright DE: The differential leucocyte count of human saliva. Arch Oral Biol 13: 1159-1161, 1968

20. Raeste AM: The differential count of oral leukocytes. Scand J Dent Res 80: 63-67, 1972

21. Skapski H and Lehner T: A crevicular washing method for investigating immune components of crevicular fluid in man J Periodontal Res 11: 19-24, 1976.

22. Kowolik MJ and Grant M: Myeloperoxidase activity in human gingival crevicular neutrophils. Arch Oral Biol 28: 293-295, 1983.

23. Smith QT and Yang CH: Salivary myeloperoxidase of young adult humans. Proc Soc Exp Biol Med 175: 468-475, 1984.

24. Vidović A, Vidović Juras D, Vučićević Boras V, Lukač J Grubišić-Ilić M, Rak D and Sabioncello A: Determination of leucocyte subsets in human saliva by flow cytometry. Arch Oral Biol 57: 577-583, 2012.

25. Calonius PE: The leukocyte count in saliva. Oral Surg Oral Med Oral Pathol 11: 43-46, 1958.

26. Woolweaver DA, Koch GG, Crawford JJ and Lundblad RL: Relation of the orogranulocytic migratory rate to periodontal disease and blood leukocyte count: A clinical study. J Dent Res 51: 929-939, 1972.

27. Cao CF and Smith QT: Crevicular fluid myeloperoxidase at healthy, gingivitis and periodontitis sites. J Clin Periodontol 16: $17-20,1989$.

28. Aune TM and Thomas EL: Accumulation of hypothiocyanite ion during peroxidase-catalysed oxidation of thiocyanate ion. Eur J Biochem 80: 209-214, 1977.

29. Aune TM and Thomas EL: Oxidation of protein sulfhydryls by products of peroxidase-catalyzed oxidation of thiocyanate ion. Biochemistry 17: 1005-1010, 1978.

30. Thomas EL, Milligan TW, Joyner RE and Jefferson MM: Antibacterial activity of hydrogen peroxide and the lactoperoxidase-hydrogen peroxide-thiocyanate system against oral streptococci. Infect Immun 62: 529-535, 1994

31. Clem WH and Klebanoff SJ: Inhibitory effect of saliva on glutamic acid accumulation by Lactobacillus acidophilus and the role of the lactoperoxidase-thiocyanate system. J Bacteriol 91: 1848-1853, 1966

32. Courtois P, Majerus P, Labbé M, Vanden Abbeele A, Yourassowsky E and Pourtois M: Susceptibility of anaerobic microorganisms to hypothiocyanite produced by lactoperoxidase. Acta Stomatol Belg 89: 155-162, 1992.

33. Ahariz M, Mouhyi J, Louette P, Van Reck J, Malevez C and Courtois P: Adsorption of peroxidase on titanium surfaces: A pilot study. J Biomed Mater Res 52: 567-571, 2000.

34. Sarr D, Tóth E, Gingerich A and Rada B: Antimicrobial actions of dual oxidases and lactoperoxidase. J Microbiol 56: 373-386, 2018 .
35. Winterbourn CC, Kettle AJ and Hampton MB: Reactive oxygen species and neutrophil function. Annu Rev Biochem 85: 765-792, 2016.

36. Redanz S, Cheng X, Giacaman RA, Pfeifer CS, Merritt J and Kreth J: Live and let die: Hydrogen peroxide production by the commensal flora and its role in maintaining a symbiotic microbiome. Mol Oral Microbiol 33: 337-352, 2018.

37. Kraus FW, Nickerson JF, Perry WI and Walker AP: Peroxide and peroxidogenic bacteria in human saliva. J Bacteriol 73: 727-735, 1957.

38. Carlsson J, Iwami Y and Yamada T: Hydrogen peroxide excretion by oral streptococci and effect of lactoperoxidase-thiocyanate-hydrogen peroxide. Infect Immun 40: 70-80, 1983.

39. Ryan CS and Kleinberg I: Bacteria in human mouths involved in the production and utilization of hydrogen peroxide. Arch Oral Biol 40: 753-763, 1995.

40. Amano A, Tamagawa H, Takagaki M, Murakami Y, Shizukuishi S and Tsunemitsu A: Relationship between enzyme activities involved in oxygen metabolism and oxygen tolerance in black-pigmented bacteroides. J Dent Res 67: 1196-1199, 1988.

41. Sheng J, Nguyen PT and Marquis RE: Multi-target antimicrobial actions of zinc against oral anaerobes. Arch Oral Biol 50: 747-757, 2005.

42. Pruitt KM, Tenovuo J, Mansson-Rahemtulla B, Harrington $P$ and Baldone DC: Is thiocyanate peroxidation at equilibrium in vivo? Biochim Biophys Acta 870: 385-391, 1986.

43. Hänström L, Johansson A and Carlsson J: Lactoperoxidase and thiocyanate protect cultured mammalian cells against hydrogen peroxide toxicity. Med Biol 61: 268-274, 1983.

44. Tenovuo J and Larjava $H$ : The protective effect of peroxidase and thiocyanate against hydrogen peroxide toxicity assessed by the uptake of $(3 \mathrm{H})$-thymidine by human gingival fibroblasts cultured in vitro. Arch Oral Biol 29: 445-451, 1984.

45. Jakubovics NS, Yassin SA and Rickard AH: Community interactions of oral streptococci. Adv Appl Microbiol 87: 43-110, 2014.

46. Sies H: Hydrogen peroxide as a central redox signaling molecule in physiological oxidative stress: Oxidative eustress. Redox Biol 11: 613-619, 2017.

47. Duan D, Scoffield JA, Zhou X and Wu H: Fine-tuned production of hydrogen peroxide promotes biofilm formation of Streptococcus parasanguinis by a pathogenic cohabitant aggregatibacter actinomycetemcomitans. Environ Microbiol 18 4023-4036, 2016.

48. Logothetopoulos JH and Myant NB: Concentration of radio-iodide and $35-\mathrm{S}$-thiocyanate by the salivary glands. J Physiol 134: 189-194, 1956.

49. Stephen KW, Robertson JW, Harden RM and Chisholm DM: Concentration of iodide, pertechnetate thiocyanate, and bromide in saliva from parotid, submandibular, and minor salivary glands in man. J Lab Clin Med 81: 219-229, 1973.

50. Felker P, Bunch R and Leung AM: Concentrations of thiocyanate and goitrin in human plasma, their precursor concentrations in brassica vegetables, and associated potential risk for hypothyroidism. Nutr Rev 74: 248-258, 2016.

51. Narkowicz S, Jaszczak E, Polkowska Ż, Kielbratowska B Kotłowska A and Namieśnik J: Determination of thiocyanate as a biomarker of tobacco smoke constituents in selected biological materials of human origin. Biomed Chromatogr 32: e4111, 2018.

52. Bourdoux P, Delange F, Gerard M, Mafuta M, Hanson A and Ermans AM: Evidence that cassava ingestion increases thiocyanate formation: A possible etiologic factor in endemic goiter. J Clin Endocrinol Metab 46: 613-621, 1978.

53. Tenovuo J and Mäkinen KK: Concentration of thiocyanate and ionizable iodine in saliva of smokers and non-smokers. J Dent Res 55: 661-663, 1976

54. Chandler JD and Day BJ: Biochemical mechanisms and therapeutic potential of the pseudohalide thiocyanate in human health. Free Radic Res 49: 695-710, 2015.

55. Schiff L, Stevens CD, Molle WE, Steinberg H, Kumpe CW and Stewart P: Gastric (and salivary) excretion of radioiodine in man Preliminary report. J Natl Cancer Inst 7: 349-354, 1947.

56. Venturi $\mathrm{S}$ and Venturi M: Iodine in evolution of salivary glands and in oral health. Nutr Health 20: 119-134, 2009.

57. Gulaboglu M, Akgül HM, Akgül N and Cetin M: Urine and saliva iodine levels in patients with dental caries and normal healthy volunteers. Trace Elem Electroly 29: 28-33, 2012.

58. Ross GR, Fabersani E, Russo M, Gómez A, Japaze H, González SN and Gauffin Cano P: Effect of excess iodide intake on salivary glands in a Swiss Albino mice model. Biomed Res Int 2017: 6302869, 2017 
59. Ren H, Qiu H, Liang X, Wang X and Jiang S: Determination of inorganic anions in saliva by electroosmotic flow controlled counterflow isotachophoretic stacking under field-amplified sample injection. J Chromatogr B Analyt Technol Biomed Life Sci 935: 75-79, 2013.

60. Novo DR, Mello JE, Rondan FS, Henn AS, Mello PA and Mesko MF: Bromine and iodine determination in human saliva: Challenges in the development of an accurate method. Talanta 191: 415-421, 2019.

61. Moss BR, Hall RF, Miller JK and Swanson EW: Effect of thiocyanate on iodide concentrating systems of the calf. Proc Soc Exp Biol Med 129: 153-155, 1968.

62. Tenovuo J: Lactoperoxidase-catalyzed iodine metabolism in human saliva. Arch Oral Biol 23: 253-258, 1978

63. Sarimo SS and Tenovuo J: Enzymically iodinated human salivary proteins. Fractionation and characterization by column chromatography and electrofocusing. Biochem J 167: 23-29, 1977.

64. Bosch EH, van Doorne H and de Vries S: The lactoperoxidase system: The influence of iodide and the chemical and antimicrobial stability over the period of about 18 months. J Appl Microbiol 89: 215-224, 2000.

65. Schlorke D, Flemmig J, Birkemeyer C and Arnhold J: Formation of cyanogen iodide by lactoperoxidase. J Inorg Biochem 154: $35-41,2016$.

66. Bafort F, Damblon C, Smargiasso N, De Pauw E, Perraudin JP and Jijakli MH : Reaction product variability and biological activity of the lactoperoxidase system depending on medium ionic strength and $\mathrm{pH}$, and on substrate relative concentration. Chem Biodivers 15: e1700497, 2018.

67. Sebaa S, Faltot M, De Breucker S, Boucherit-Otmani Z, Bafort F, Perraudin JP and Courtois Ph: Ex vivo decontamination of yeast-colonized dentures by iodine-thiocyanate complexes. Clin Cosmet Investig Dent 10: 149-158, 2018.

68. Tonoyan L, Boyd A, Fleming GTA, Friel R, Gately CM, Mc Cay PH and O'Flaherty V: In vitro comparative cytotoxicity study of a novel biocidal iodo-thiocyanate complex. Toxicol In Vitro 50: 264-273, 2018.

69. Pruitt KM,Mansson-Rahemtulla B, Baldone DC and Rahemtulla F: Steady-state kinetics of thiocyanate oxidation catalyzed by human salivary peroxidase. Biochemistry 27: 240-245, 1988.

70. Ashby MT: Inorganic chemistry of defensive peroxidases in the human oral cavity. J Dent Res 87: 900-914, 2008.

71. Pruitt KM, Mansson-Rahemtulla B and Tenovuo J: Detection of the hypothiocyanite (OSCN-) ion in human parotid saliva and the effect of $\mathrm{pH}$ on $\mathrm{OSCN}$ - generation in the salivary peroxidase antimicrobial system. Arch Oral Biol 28: 517-525, 1983.

72. Thomas EL, Bates KP and Jefferson MM: Hypothiocyanite ions: Detection of the antimicrobial agent in human saliva. J Dent Res 59: 1446-1472, 1980

73. Pruitt KM, Kamau DN, Miller K, Månsson-Rahemtulla B and Rahemtulla F: Quantitative, standardized assays for determining the concentrations of bovine lactoperoxidase, human salivary peroxidase, and human myeloperoxidase. Anal Biochem 191: 278-286, 1990

74. Bafort F, Barthelemy JP, Parisi O, Perraudin JP and Jijakli HM: Development of a colorimetric method for the dosage of OIanions and I2 in aqueous media. Commun Agric Appl Biol Sci 79: 155-160, 2014

75. Thibodeau EA, Bowen WH and Marquis RE: pH-dependent fluoride inhibition of peroxidase activity. J Dent Res 64: 1211-1213, 1985.

76. Mansson-Rahemtulla B, Baldone DC, Pruitt KM and Rahemtulla F: Specific assays for peroxidases in human saliva. Arch Oral Biol 31: 661-668, 1986.

77. White WE Jr, Pruitt KM and Mansson-Rahemtulla B Peroxidase-thiocyanate-peroxide antibacterial system does not damage DNA. Antimicrob Agents Chemother 23: 267-272, 1983.

78. Altman LC, Baker C, Fleckman P, Luchtel D and Oda D: Neutrophil-mediated damage to human gingival epithelial cells. J Periodontal Res 27: 70-79, 1992

79. Ahariz M and Courtois P: Candida albicans susceptibility to lactoperoxidase-generated hypoiodite. Clin Cosmet Investig Dent 2: 69-78, 2010 .

80. Molloy C, Shepherd MG and Sullivan PA: Identification of envelope proteins of Candida albicans by vectorial iodination. Microbios 57: 73-83, 1989.

81. Fischer AJ, Lennemann NJ, Krishnamurthy S, Pócza P, Durairaj L, Launspach JL, Rhein BA, Wohlford-Lenane C, Lorentzen D, Bánfi B, and McCray PB Jr: Enhancement of respiratory mucosal antiviral defenses by the oxidation of iodide. Am J Respir Cell Mol Biol 45: 874-881, 2011.
82. Derscheid RJ, van Geelen A, Berkebile AR, Gallup JM, Hostetter SJ, Banfi B, McCray PB Jr and Ackermann MR: Increased concentration of iodide in airway secretions is associated with reduced respiratory syncytial virus disease severity. Am J Respir Cell Mol Biol 50: 389-397, 2014.

83. Shoemake BM, Vander Ley BL, Newcomer BW and Heller MC: Efficacy of oral administration of sodium iodide to prevent bovine respiratory disease complex. J Vet Intern Med 32: 516-524, 2018

84. Kumlien A, Carlsöö B and Bloom GD: Iodide accumulation and peroxidase activity in the submandibular salivary gland of the normal and castrated male hamster. Arch Oral Biol 19: 577-582, 1974.

85. Tsuda S, Soutome S, Hayashida S, Funahara M, Yanamoto S and Umeda M: Topical povidone iodine inhibits bacterial growth in the oral cavity of patients on mechanical ventilation: A randomized controlled study. BMC Oral Health 20: 62, 2020

86. Bafort F, Parisi O, Perraudin JP and, Jijakli H: The lactoperoxidase system: A natural biochemical biocontrol agent for pre- and post-harvest applications. J Phytopathol 165: 22-34, 2017

87. Lewis C and Skoog DA: Spectrophotometric study of a thiocyanate complex of iodine. J Am Chem Soc 84: 1101-1106, 1962.

88. Long C and Skoog DA: A thiocyanate complex of Iodine (I). Inorg Chem 5: 206-210, 1966.

89. Országh I, Bazsa G and Beck MT: Spectrophotometric study of the reversible iodine-thiocyanate interaction. Inorganica Chim Acta 6: 271-274, 1972.

90. Scott McIndoe J and Tuck DG: Studies of polyhalide ions in aqueous and non-aqueous solution by electrospray mass spectrometry. Dalt Trans 2003: 244-248, 2003.

91. Courtois PH and Pourtois M: Purification of NADH Hypothiocyanite oxidoreductase in Streptococcus sanguis. Biochem Mol Med 57: 134-138, 1996

92. Tonoyan L, Fleming GTA, Mc Cay PH, Friel R and O'Flaherty V: Antibacterial potential of an antimicrobial agent inspired by peroxidase-catalyzed systems. Front Microbiol 8: 680, 2017.

93. Tenovuo J and Pruitt KM: Relationship of the human salivary peroxidase system to oral health. J Oral Pathol 13: 573-584, 1984.

94. Hogg DM and Jago GR: The oxidation of reduced nicotinamide nucleotides by hydrogen peroxide in the presence of lactoperoxidase and thiocyanate, iodide or bromide. Biochem J 117 791-797, 1970

95. Tenovuo J, Mansson-Rahemtulla B, Pruitt KM and Arnold R Inhibition of dental plaque acid production by the salivary lactoperoxidase antimicrobial system. Infect Immun 34: 208-214, 1981.

96. Ihalin R, Loimaranta V, Lenander-Lumikari M and Tenovuo J: The effects of different (pseudo)halide substrates on peroxidase-mediated killing of Actinobacillus actinomycetemcomitans. J Periodontal Res 33: 421-427, 1998.

97. Fadel $\mathrm{M}$ and Courtois P: Effect of peroxidase-generated hypothiocyanite on the survival rate of Porphyromonas gingivalis NCTC 11834. Med Sci Res 27: 667-669, 1999.

98. Fadel $\mathrm{M}$ and Courtois P: Inhibitory effect of lactoperoxidase-generated hypothiocyanite upon black pigmented anaerobe growth. Int J Mol Med 8: 59-62, 2001.

99. Majerus PM and Courtois PA: Susceptibility of Candida albicans to peroxidase-catalyzed oxidation products of thiocyanate, iodide and bromide. J Biol Buccale 20: 241-245, 1992.

100. Courtois P, van Beers D, de Foor M, Mandelbaum IM and Pourtois M: Abolition of herpes simplex cytopathic effect after treatment with peroxidase generated hypothiocyanite. J Biol Buccale 18: 71-74, 1990.

101. Pourtois M, Binet C, Van Tieghem N, Courtois P, Vandenabbeele A and Thiry L: Saliva can contribute in quick inhibition of HIV infectivity. AIDS 5: 598-600, 1991.

102. Cegolon L, Salata C, Piccoli E, Juarez V, Palu' G, Mastrangelo G and Calistri A: In vitro antiviral activity of hypothiocyanite against A/H1N1/2009 pandemic influenza virus. Int J Hyg Environ Health 217: 17-22, 2014

103. Patel U, Gingerich A, Widman L, Sarr D, Tripp RA and Rada B: Susceptibility of influenza viruses to hypothiocyanite and hypoiodite produced by lactoperoxidase in a cell-free system. PLoS One 13: e0199167, 2018

104. Cegolon L, Javanbakht M and Mastrangelo G: Nasal disinfection for the prevention and control of COVID-19: A scoping review on potential chemo-preventive agents. Int J Hyg Environ Health 230: 113605, 2020 
105. Nguyen GT, Green ER and Mecsas J: Neutrophils to the ROScue: Mechanisms of NADPH oxidase activation and bacterial resistance. Front Cell Infect Microbiol 7: 373, 2017.

106. Carlsson J: Salivary peroxidase: An important part of our defense against oxygen toxicity. J Oral Pathol 16: 412-416, 1987.

107. Cáp M, Váchová L and Palková Z: Reactive oxygen species in the signaling and adaptation of multicellular microbial communities. Oxid Med Cell Longev 2012: 976753, 2012.

108.van Steenberghe D, Van den Eynde E, Jacobs R and Quirynen M: Effect of a lactoperoxidase containing toothpaste in radiation-induced xerostomia. Int Dent J 44: 133-138, 1994.

109. Lenander-Lumikari M, Månsson-Rahemtulla B and Rahemthulla F: Lysozyme enhances the inhibitory effects of the peroxidase system on glucose metabolism of Streptococcus mutans. J Dent Res 71: 484-490, 1992

110. Sardaro N, Della Vella F, Incalza MA, DI Stasio D, Lucchese A, Contaldo M, Laudadio C and Petruzzi M: Oxidative stress and oral mucosal diseases: An overview. In Vivo 33: 289-296, 2019.

111. Magacz M,Kędziora K, Sapa J and Krzyściak W: The significance of lactoperoxidase system in oral health: Application and efficacy in oral hygiene products. Int J Mol Sci 20: 1443, 2019.

112. Mansson-Rahemtulla B, Pruitt KM, Tenovuo J and Le TM: A mouthrinse which optimizes in vivo generation of hypothiocyanite. J Dent Res 62: 1062-1066, 1983

113. FAO/WHO report: Benefits and potential risks of the lactoperoxidase system of raw milk preservation. Report of an FAO/WHO technical meeting, FAO Headquarters, Rome, Italy, 28 November-2 December 2005, 2006

114. Artym J and Zimecki M: Milk-derived proteins and peptides in clinical trials. Postepy Hig Med Dosw (Online) 67: 800-816, 2013

115. Welk A, Meller CH, Schubert R, Schwahn CH, Kramer A and Below $\mathrm{H}$ : Effect of lactoperoxidase on the antimicrobial effectiveness of the thiocyanate hydrogen peroxide combination in a quantitative suspension test. BMC Microbiol 9: 134, 2009.

116. Modesto A, Lima KC and de Uzeda M: Effects of three different infant dentifrices on biofilms and oral microorganisms. J Clin Pediatr Dent 24: 237-243, 2000.

117. Tenovuo J: Clinical applications of antimicrobial host proteins lactoperoxidase, lysozyme and lactoferrin in xerostomia: Efficacy and safety. Oral Dis 8: 23-29,2002

118. Vanden Abbeele A, De Meel H, Courtois P and Pourtois M: Influence of a hypoiodite mouth-wash on dental plaque formation in vivo. Bull Group Int Rech Sci Stomatol Odontol 39: 57-61, 1996.

119. Nakano M,WakabayashiH,Sugahara H,Odamaki TYamauchiK, Abe F, Xiao JZ, Murakami K, Ishikawa K and Hironaka S: Effects of lactoferrin and lactoperoxidase-containing food on the oral microbiota of older individuals. Microbiol Immunol 61: 416-426, 2017.

120. Lenander-Lumikari M, Tenovuo J and Mikola H: Effects of a lactoperoxidase system-containing toothpaste on levels of hypothiocyanite and bacteria in saliva. Caries Res 27: 285-291, 1993

121. Koch G, Edlund K and Hoogendoorn H: Lactoperoxidase in the prevention of plaque accumulation, gingivitis and dental caries. II. Effect of mouthrinses with amyloglucosidase and glucoseoxidase on plaque accumulation on teeth in individuals on a sucrose diet. Odontol Revy 24: 367-372, 1973

122. Hugoson A, Koch G, Thilander $\mathrm{H}$ and Hoogendoorn $\mathrm{H}$ : Lactoperoxidase in the prevention of plaque accumulation, gingivitis and dental caries. 3. Effect of mouthrinses with amyloglucosidase and glucoseoxidase in the model system of experimental gingivitis and caries in man. Odontol Revy 25 69-80, 1974

123. Koch G and Strand G: Effect of an enzyme dentifrice on caries. A two-year clinical pilot study. Swed Dent J 3: 9-13, 1979.

124. Rotgans J and Hoogendoorn H: The effect of brushing with a toothpaste containing amyloglucosidase and glucose oxidase on dental caries in rats. Caries Res 13: 150-153, 1979.

125. Afseth J and Rølla G: Clinical experiments with a toothpaste containing amyloglucosidase and glucose oxidase. Caries Res 17: 472-475, 1983.

126. Midda $M$ and Cooksey MW: Clinical uses of an enzyme-containing dentifrice. J Clin Periodontol 13: 950-956, 1986.
127. Bánóczy J, Dombi C, Czegledly A and Sari K: A clinical study with lactoperoxidase-containing gel and toothpaste in patients with dry mouth syndrome. J Clin Dent 5: 65-69, 1994.

128. Toljanic JA, Siddiqui AA, Patterson GL and Irwin ME: An evaluation of a dentifrice containing salivary peroxidase elements for the control of gingival disease in patients with irradiated head and neck cancer. J Prosthet Dent 76: 292-296, 1996.

129. Epstein JB, Emerton S, Le ND and Stevenson-Moore P: A double-blind crossover trial of Oral Balance gel and Biotene ${ }^{\circledR}$ toothpaste versus placebo in patients with xerostomia following radiation therapy. Oral Oncol 35: 132-137, 1999.

130. Warde P, Kroll B, O'Sullivan B, Aslanidis J, Tew-George E, Waldron J, Maxymiw W, Liu FF, Payne D and Cummings B A phase II study of Biotene in the treatment of postradiation xerostomia in patients with head and neck cancer. Support Care Cancer 8: 203-208, 2000

131. Kirstilä V, Lenander-Lumikari M, Söderling E and Tenovuo J: Effects of oral hygiene products containing lactoperoxidase, lysozyme, and lactoferrin on the composition of whole saliva and on subjective oral symptoms in patients with xerostomia. Acta Odontol Scand 54: 391-397, 1996.

132. Matear DW and Barbaro J: Effectiveness of saliva substitute products in the treatment of dry mouth in the elderly: A pilot study. J R Soc Promot Health 125: 35-41, 2005.

133. Hatti S, Ravindra S, Satpathy A, Kulkarni RD and Parande MV: Biofilm inhibition and antimicrobial activity of a dentifrice containing salivary substitutes. Int J Dent Hyg 5: 218-224, 2007.

134. Gil-Montoya JA, Guardia-López I and González-Moles MA Evaluation of the clinical efficacy of a mouthwash and oral gel containing the antimicrobial proteins lactoperoxidase, lysozyme and lactoferrin in elderly patients with dry mouth-a pilot study. Gerodontology 25: 3-9, 2008.

135. Shin K, Yaegaki K, Murata T, Ii H, Tanaka T, Aoyama I, Yamauchi K, Toida T and Iwatsuki K: Effects of a composition containing lactoferrin and lactoperoxidase on oral malodor and salivary bacteria: A randomized, double-blind, crossover, placebo-controlled clinical trial. Clin Oral Investig 15: 485-493, 2011.

136. Jose A, Siddiqi M, Cronin M, DiLauro TS and Bosma ML: A randomized clinical trial in subjects with dry mouth evaluating subjective perceptions of an experimental oral gel, an oral rinse and a mouth spray compared to water. Am J Dent 29: 58-64, 2016.

137. Nakano M, Shimizu E, Wakabayashi H, Yamauchi K and Abe F A randomized, double-blind, crossover, placebo-controlled clinical trial to assess effects of the single ingestion of a tablet containing lactoferrin, lactoperoxidase, and glucose oxidase on oral malodor. BMC Oral Health 16: 37, 2016.

138. Morita Y, Ishikawa K, Nakano M, Wakabayashi H, Yamauchi K, Abe F, Ooka T and Hironaka S: Effects of lactoferrin and lactoperoxidase-containing food on the oral hygiene status of older individuals: A randomized, double blinded, placebo-controlled clinical trial. Geriatr Gerontol Int 17: 714-721, 2017.

139. Barbe AG, Schmidt-Park Y, Hamacher S, Derman SHM and Noack MJ: Efficacy of GUM ${ }^{\circledR}$ Hydral versus Biotène ${ }^{\circledR}$ Oralbalance mouthwashes plus gels on symptoms of medication-induced xerostomia: A randomized, double-blind, crossover study. Clin Oral Investig 22: 169-180, 2018.

140. Nakano M, Yoshida A, Wakabayashi H, Tanaka M, Yamauchi K, Abe F and Masuda Y: Effect of tablets containing lactoferrin and lactoperoxidase on gingival health in adults: A randomized, double-blind, placebo-controlled clinical trial. J Periodontal Res 54: 702-708, 2019.

141. Pruitt KM, Tenovuo J, Fleming W and Adamson M: Limiting factors for the generation of hypothiocyanite ion, an antimicrobial agent, in human saliva. Caries Res 16: 315-323, 1982.

142. Sebaa S, Lybaert P, Boucherit-Otmani Z, Courtois PH and Ahariz M: Ex vivo yeast-decontamination of denture by $\mathrm{H}_{2} \mathrm{O}_{2}$ /Iodide/Lactoperoxidase system: Need to overpass the microbial $\mathrm{H}_{2} \mathrm{O}_{2}$ catabolism. Oral Health Dent Manag 14: 62-69, 2015.

143. Herlofson BB and Barkvoll P: Sodium lauryl sulfate and recurrent aphthous ulcers. A preliminary study. Acta Odontol Scand 52: 257-259, 1994.

144. Cawley A, Golding S, Goulsbra A, Hoptroff M, Kumaran S and Marriott R: Microbiology insights into boosting salivary defences through the use of enzymes and proteins. J Dent 80 (Suppl 1): S19-S25, 2019 
145. Adams SE, Arnold D, Murphy B, Carroll P, Green AK, Smith AM, Marsh PD, Chen T, Marriott RE and Brading MG: A randomised clinical study to determine the effect of a toothpaste containing enzymes and proteins on plaque oral microbiome ecology. Sci Rep 7: 43344, 2017.

146. Memarzadeh Zahedani M, Schwahn C, Baguhl R, Kocher T, Below $\mathrm{H}$ and Welk A: Association of salivary peroxidase activity and concentration with periodontal health: A validity study. J Clin Periodontol 44: 803-812, 2017.

147. Herrero ER, Boon N, Bernaerts K, Slomka V, Verspecht T, Quirynen M and Teughels W: Clinical concentrations of peroxidases cause dysbiosis in in vitro oral biofilms. J Periodontal Res 53: 457-466, 2018
148. Miller DP, Fitzsimonds ZR and Lamont RJ: Metabolic signaling and spatial interactions in the oral polymicrobial community. J Dent Res 98: 1308-1314, 2019.

149. Diaz PI and Valm AM: Microbial interactions in oral communities mediate emergent biofilm properties. J Dent Res 99: 18-25, 2020.

This work is licensed under a Creative Commons Attribution-NonCommercial-NoDerivatives 4.0 International (CC BY-NC-ND 4.0) License. 